1894 the two announced to an incredulous audience that the atmosphere contained a new gaseous element. Working independently, the two had reached the same result and the discovery was announced by them jointly. The full account of the work was given to a meeting of the Royal Society in January 1895. By then the density of the gas was found; it had been shown to be monatomic from the ratio $c_{p} / c_{v}$ of its specific heats as approximately $1 \cdot 66$, and its atomic weight was $39 \cdot 9$. 'T'he new gas was given the name 'argon'.

'T'he day after the paper was read, Henry Miers, the mineralogist, directed Ramsay's attention to a gas evolved on heating uranium minerals and thought to be nitrogen. It might, he said, be argon. Ramsay prepared this gas, found that it gave a bright yellow line in the spectrum, and was inert. Crookes, with a sample of the gas sent him by Ramsay, identified the spectrum line with one which had been observed in the solar spectrum during the eclipse of 1868 by Lockyer, and supposed by him to belong to an element present in the sun to which he gave the name 'helium'. The new gas had, therefore, already been named. By the end of 1898 Ramsay, working with Travers, had discovered three more inert gases, neon, krypton and xenon, and with one exception the new group in the Periodic Table was filled. The remaining clement linked this work with another field in which Ramsay made notable discoveries.

The year 1898, when the tale of the atmospheric inert gases had been told, saw the beginning of an epoch of scientific discovery without parallel in anything which had gone before. Radium was discovered by Mme. Curie. It was soon shown that radium emitted a radioactive gas called the emanation of radium (now radon). This was of great interest to Ramsay, who began work on the subject. His splendid manipulative skill, highly developed by having. to deal with minute volumes of rare gases, was needed in handling extremely small quantities of radioactive emanation. In collaboration with Soddy, Ramsay soon showed that radon is an inert gas and that on standing it slowly changes into helium. In 1912 Ramsay and Whytlaw-Gray published the results of a determination of the density of radon in which only about a tenth of a cubic millimetre of gas was weighed on a micro-balance sensitive to two-millionths of a milligram. The atomic weight of radon found agreed with the assumption that it was formed from radium, atomic weight 226 , by the emission of an alpha-particle which was chemically the same as a helium atom of weight 4 ; hence the atomic weight of radon should be 222 , while the value 223 was found from the density on the assumption that it was monatomic. Radon then took its place as the last element in the inert gas group.

Ramsay's later work in the field of radioactivity was less successful and he was led astray by supposed transformations of elements, such as copper into lithium, under the influence of radioactivity. He realized, however, that the great concentration of energy made available in radioactivity was likely to lead to such transformations, a prediction achieved by later workers in this field. Ramsay took a great interest in the earlier applications of radioactive materials in medicine.

Ramsay was knighted in 1902 and his work on the inert gases gained for him the Nobel Prize in 1904. His administrative talent has already been mentioned, and during his tenure of the professorship at University College he was a president of the Society of
Chemical Industry, of the Chemical Society, and of the British Association. He also took a keen interest in the character of the University of London, as a result of which and of the efforts of others, the University changed its former character of being a purely examining body and incorporated the constituent colleges as tcaching institutions, at the same time giving their teachers a share in the examinations and the determination of the places of the candidates. Since then, the internal side of the University has greatly increased in importance and influence.

Ramsay had the keenest interest in research, inspiring his students and encouraging them by his example. Many of them have filled positions of distinction. At the end of the session of 1912 Ramsay retired from the professorship at University College. $\mathrm{He}$ was looking forward to the continuation of research ; but this was not to be. He died on July 23, 1916, after a painful illness.

Kindly and sympathetic towards his students, friendly and courteous to his colleagues, enthusiastic and active in his work, Ramsay left memories of a great man, which he undoubtedly was. After his death, funds raised by public subscription were partly devoted to the building of a Chemical Engineering Laboratory at University College and partly to the foundation of a Ramsay Memorial Fellowship for advanced students of chemistry. At present, owing to monetary depreciation, the number of fellowships has had to be reduced to half the original number, and the University College Committee and the Ramsay Memorial Fellowships Trustees decided that the centenary of the birth of Sir William Ramsay should be made the occasion of a joint appeal for a total of $£ 100,000$, partly to restore the number of fellowships and partly to extend the chemical laboratories at University College. Both these objects, it is believed, would further the interests of the extension of scientific knowledge which were Ramsay's interests, and also, since the fellowships are international in principle, are in harmony with his constant desire to advance friendship and helpful collaboration among all scientific men. The Appeals Secretary, Ramsay Centenary Appeal, University College, Gower Street, London, W.C.I, will receive contributions from all who wish to help this cause and will give further information about the appeal. The Science Museum, South Kensington, has also organized a Ramsay Centenary Exhibition in collaboration with University College, which was opened on October 2 by Lord Woolton, Lord President of the Council, and will remain open to the public for three months (see p. 562).

\section{FACTORS AFFECTING CHOICE AND JUDGMENT}

T had been the intention to take advantage of the 1 meeting of the British Association at Belfast to follow up the work of the informal conference on "Subjective Judgments" held in London in October 1950. It proved, however, to be difficult to realize this object within the present framework of the British Association, so that instead a series of papers were given which were not directly related to the work of the previous conference, the general title of the papers being "Some Factors affecting Choice and Judgment". Two of the papers, from the Road 
Research Laboratory, Harmondsworth, dealt with social factors which affect the actions of road users; the other papers were of a more theoretical nature and dealt with factors affecting perceiving and judging under experimental, rather than everyday, conditions.

The attitude of the general science graduate to experiments involving subjective judgments is curious and illogical, even if understandable. $\mathrm{He}$ is taught throughout his study period to believe that those things which he measures during the course of his 'practical work' are facts, inviolable and true. His faith in them transcends the faith of religion. Above all, he believes in the dogma of Kelvin, that we must measure to be able to understand. He rarely succeeds in grasping the principles of uncertainty in physical measurement, and many years may pass before he realizes that all measurement demands a judgment on the compromise betwcen accuracy and expediency. As a result, he dismisses all experiments which involve direct subjective judgments as being "vague and inaccurate'. This dogmatic attitude is not confined to the young graduate. It finds its way into higher levels, where great efforts are made to develop physical analogues to supplant the human observer in a perceptual situation. Consequently, it happens that the experimenter who uses human subjects as indicators finds it necessary to go to unusual lengths to explain his means as well as his ends. Modern statistical methods have assisted greatly in the discipline of subjective judgment experiments. They serve in three ways: to enable the experiments to be designed on sound lines; to enable the results to be interpreted by a logical procedure rather than by inspection and induction alone; and to enable the results to be presented in a way which carries some conviction with the worker who believes that physical instruments alone can be used as indicators in experiments.

Statistical technique is a good servant, but an exacting master ; it is appalling to contemplate the amount of observational and analytical work necessary to demonstrate statistically a factor the existence of which common sense has never had any reason to doubt. This must have struck forcibly those who participated in the Belfast symposium; but little improvement is likely to result until there is a change of heart in favour of a greater faith in the very real ability of human observers to give reliable judgments of their environment. The nature of this ability was demonstrated by Dr. R. G. Hopkinson, of the Building Research Station, Garston, who reported assessments of glare discomfort made under controlled conditions over a period of more than three years. With nothing to guide them but their sensations of glare discomfort, subjects had made settings of the physical variable controlling the sensation; the results showed only a very small variation in the mean values. Subjects who had passed through an initial 'sensitization period' could be relied upon to reproduce their findings to a useful order of repetition accuracy.

These findings apply to the conditions of a laboratory experiment. The work reported by the Road Research Laboratory was done under more natural conditions, records being made of the behaviour of road users, both drivers and pedestrians, to determine how this behaviour could be improved. The findings must be of interest to sociologists as well as to those concerned only with road safety problems. The work on driver behaviour suggests that improvement cannot result from legal restrictions alone unless there is a very great certainty of enforcement. Legal restrictions must be combined with clear evidence of the inevitability of enforcement, such as the presence of a policeman in a strategic position, or with clear evidence of the inevitability of physical retributiondrivers will stop at a "Halt, major road ahead" sign if there is clear evidence of the existence of fast traffic on the major road. The same effects are observable on pedestrians ; a policeman at a crossing has a significant effect on those (chiefly men, it would appear) whose normal behaviour at crossings is irregular.

The effect of propaganda on the behaviour of both drivers and pedestrians could be demonstrated clearly; but propaganda alone is insufficient to maintain any permanent improvement. An example is that of the behaviour of both drivers and pedestrians on crossings. Propaganda alone improved behaviour at ordinary crossings, but not for long. But propaganda added to the striping of crossings in the zebra pattern produced a more marked effect, and one which remained, not indeed at the peak level attained during the initial stages, but nevertheless substantial.

These findings can be interpreted charitably on the assumption that the driver and pedestrian are sensible adults. A driver will not obey legal restrictions unless there are manifest reasons why he should. In the absence of visible evidence of retribution, he will behave as common sense dictates. $\mathrm{He}$ will not obey a speed restriction if there are no obvious hazards, nor will he stop at a road ahead if it is not likely to require such action. A pedestrian will not use a crossing unless it is clearly beyond his ability to get across the road without its aid. But equally the findings can be interpreted on the assumption that he is little more than a juvenile delinquent. This was the interpretation made in the paper by Mr. B. M. Foss, of Birkbeck College, London, with especial reference to the personality of the 'car-plus-driver'. On this interpretation the road user is anti-social, and will do any un-neighbourly action which he thinks he can 'get away with'. The car driver can be expected to enlarge his 'body-image' in relation to the size and horse-power of his car, just as a man with a hat allows for his increased height in going under a low doorway. The bodyimage governs behaviour in a social as well as a physical sense. The driver with a large car finds himself in a position of power, and his tendency is to exercise it to his own advantage, unless he is warned, say by the presence of a policeman, of the inevitable retribution which such behaviour will bring.

There is a good reason for believing that much can be explained by the faith which the human subject has in his own abilities to make accurate judgments - a faith which, as has been suggested, is not shared by scientists nurtured in the nineteenth-century tradition. The pedestrian crosses the road without troubling to find a crossing, because he is sure that he can judge the distance and the speed of an oncoming vehicle, and hence is certain that he will be across before the vehicle can hit him. On the average his faith is justified, as the estimates given by the Road Research Laboratory show. But of course it is not the average man who gets knocked over. The distribution and variance of the speed estimates given by the work of the Laboratory show that there are occasions when the speed of an oncoming vehicle is 
grossly underestimated. Mr. Foss directed attention to the fact that these lapses are more frequent in the neurotic and the fatigued; but many experiments, including those of the long series of judgments reported by Dr. Hopkinson, show that even the experienced subject will on occasions show a wide departure from his average judgment. If the 'average man' appreciated that his errors of judgment might on, say, one occasion in fifty involve him in a potentially fatal situation, he might exercise more caution--but equally he might still take the risk.

In any experiment or situation involving subjective judgments, the apparent inevitability of big random errors must not be neglected. If a large number of observers can make the judgment, these errors can be expected to cancel out. In practice it is often difficult or impossible to obtain sufficient observers; the work has to be done with a small team, and Dr. Hopkinson's paper dealt with some of the problems which arise in such a case. Experience of the experimental situation clearly has an effect. In the case of glare discomfort, there is a demonstrable increase in sensitivity from day to day, apart from the random errors. After this 'sensitization period' is passed, the subject appears to maintain his criterion of sensation over a very long period, with a fairly constant variance. It is therefore possible to decide the number of observations necessary from this observer in order to eliminate, to a predetermined degree of probability, the random errors in his observations. Consequently, an experiment employing a team of observers can be designed with a certain precision. It remains to link the results with those which would be expected to be obtained from a representative selection of the population under the same conditions. This has been done for a few of the important situations, and it has been found that about four-fifths of the general population are satisfied, or more than satisfied, with the average opinion of the team of experienced subjects. This applies, of course, to the particular problem of glare in lighting, but the same procedure is applicable to other perceptual situations.

The exact reason for this 'experience effect' in subjective judgments did not emerge from the discussion. It may be some form of accumulative memory-trace effect which should be capable of explanation. It might well link up with studies of modern information theory. The techniques of the building Research Station experiments, which demand the control and variation by the subject of the physical variable governing the sensation, involve the feed-back of information of the situation, which must necessarily influence the judgment. These factors need study and explanation. The judgment is certainly influenced by the environment. This has been shown to be true in the judgment of spatial direction, as was demonstrated in the paper by Miss M. A. Phemister, of the Psychology Department, Queen's University, Belfast. There are preferred frames of reference, which assist judgment. If the body is vertical, the subject can judge position and direction accurately, but if it is tilted, this facility is to some extent lost. The apparent size of an object depends not only on the angular subtense of the object at the eye, but also on its position in the frame of reference. The moon near the horizon looks bigger than when well up, to such an extent that all kinds of explanations of the effect are made in terms of refraction distortions-another example of the inclination of some trained scientists to search for an objective rather than a subjective explanation of a phenomenon.

One would have hoped that some discussion would have arisen on the training of subjects to make judgments : whether such training is advisable, and if so, what form it should take. 'I'his important point was unfortunately not taken up. Mr. Foss, in his paper, gave a clear lead in his suggestion that 'intuition' is a facility that should be recognized as a valuable ability in clinicians and interviewers, for example, and that persons of good intuition should be found and trained, over and above the need, already recognized, for the training of subjects to make finer discriminations of a situation with greater accuracy. Dr. Hopkinson suggested that observers should have certajn valuable personal characteristics. They should have a social conscience, and give of their best, without needing to be encouraged by a knowledge of the trend of their results-indeed, they must not have any preconceived theory about the experiment on which they are asked to make judgments ; otherwise their 'coefficient of involuntary mendacity' may cause deviations or over-compensation. Their social conscience should extend only to a desire for the success of the experiment, and not to an interest in its result. Personal characteristics may also influence the kind of criteria which form the basis of the judgment. Mir. Foss suggested that some subjects may work better with broad categories; others may prefer to exercise their abilities to make fine discriminations within narrow categories, and hence these people may be suitable for different experiments from the former. This is a valuable and interesting suggestion which may merit close attention by those engaged on the development of the discipline of subjective judgment experiments. K. G. HopkINSON

\section{BOTANY OF FLAX}

TN introducing a meeting on the "Botany of Flax", 1 held in Belfast on September 8 by Section $K$ (Botany) of the British Association, Major G. O. Searle, of H.M. Norfolk Flax Establishment, referred to the importance of the flax plant as a major factor in building up the prosperity of Belfast and Northern Ireland in general. Although in Ernst Schilling's "Die Faserstoffe" more than nineteen hundred plant species are listed as being capable of yielding fibre of industrial use, the best of all-that is, Linum spp.were utilized in the Middle East seven thousand years or more ago. It has been suggested by some that Linum angustifolium Huds. was the species first used for the manufacture of linen; but it is clear that for many centuries Linum usitatissimum L. has held the field; the taller fine-stemmed varieties are used for the production of fibre, and the shorter branchingvarieties for linseed. The chief interest of linen flax lies in its fibre system and in the attempt to produce improved types by breeding, the quantity and quality of the fibre being the salient factors concerned. From 1880 onwards, flax growing in the British Isles has been mostly centred in Northern Ireland where, owing to the practice of 'dam retting', the seed is lost. Consequently, all sowing seed was imported from Russia and the Baltic countries or from Holland. Distinctive varieties as such were not available, and the brands of seed largely used were known as Riga 